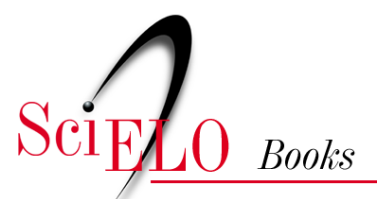

\title{
Capítulo 2. Povos Indígenas no Alto Rio Negro um estudo de caso de nupcialidade
}

\author{
Marta Maria Azevedo
}

\section{SciELO Books / SciELO Livros / SciELO Libros}

AZEVEDO, M.M. Povos Indígenas no Alto Rio Negro: um estudo de caso de nupcialidade. In: PAGLIARO, H., AZEVEDO, MM., and SANTOS, RV., comps. Demografia dos povos indígenas no Brasil [online]. Rio de Janeiro: Editora FIOCRUZ, 2005, pp. 33-57. Saúde dos Povos Índigenas collection. ISBN: 978-85-7541-254-1. https://doi.org/10.7476/9788575412541.0003.

\section{(1)(1)(2)}

All the contents of this work, except where otherwise noted, is licensed under a Creative Commons Attribution-Non Commercial-ShareAlike 3.0 Unported.

Todo o conteúdo deste trabalho, exceto quando houver ressalva, é publicado sob a licença Creative Commons Atribuição - Uso Não Comercial - Partilha nos Mesmos Termos 3.0 Não adaptada. 


\section{Povos Indígenas no Alto Rio Negro: um estudo de caso de nupcialidade}

\section{Introdução}

Diversos estudos sobre a demografia dos povos indígenas no Brasil relacionam componentes demográficos à estrutura social desses povos, como o de Pagliaro (2002), sobre os Kaiabi do Parque Indígena do Xingu, onde a autora relaciona os tipos de casamentos existentes com a organização social e a migração do grupo para o Xingu, demonstrando que muitas vezes constrangimentos demográficos podem causar rearranjos nos sistemas tradicionais de escolhas matrimoniais. Ao descrever os casamentos realizados entre homens kaiabi e mulheres juruna, suiá, trumai e txicão nos primeiros anos de permanência do grupo no Parque Indígena do Xingu, a autora avalia "... como estas uniões foram absorvidas pelo grupo, para que a reposição populacional não fosse ameaçada, mostrando como um problema demográfico pode modificar temporariamente arranjos familiares e culturais" (Pagliaro, 2002:153). Ainda sobre rearranjos matrimoniais, Laraia (1963) observa que entre os Suruí, após um longo período de depopulação causado por epidemias, uma mulher poderia estar casada com mais de um homem ao mesmo tempo, o que não era o comportamento tradicional deste grupo. O autor observa também que, na época em que trabalhou com os Suruí, muitas mulheres mantinham relações sexuais freqüentes com outros homens na ausência de seus maridos. A definição da paternidade social das crianças geradas a partir desses rearranjos variou, mas não o pertencimento aos clãs, que seguiu sendo pela via do marido da mãe, e não dos seus eventuais parceiros sexuais.

Trabalhos como os de Pozzobon (1994) sobre o mínimo populacional necessário para que uma determinada estrutura social possa se reproduzir, ou como o de Adams (1994), já relacionavam os padrões demográficos de nupcialidade aos tipos de organização social. Pozzobon descreve como uma população teórica, com uma estrutura social fundamentada em metades exogâmicas e determinada terminologia de parentesco, pode se reproduzir, e qual o número mínimo de pessoas necessário para esta reprodução. Adams em seu trabalho sobre os Caribe do rio 
Baráma, da Guiana Inglesa, discorre sobre rearranjos matrimoniais decorrentes de pressões demográficas causadas por questões econômicas e deslocamentos populacionais. Outro trabalho, como o de Coimbra Jr. et al. (2002) sobre a dinâmica demográfica dos Xavánte, relaciona as conseqüências de crises demográficas causadas pelo contato com os não-índios a fatores relativos à organização social deste povo.

A região do alto rio Negro, no lado brasileiro, é atualmente habitada por 21 povos indígenas ${ }^{1}$ falantes de línguas das famílias Tukano, Aruak e Maku. Faz fronteira com a Colômbia e Venezuela, e, em 1998, teve cinco terras indígenas (T.I.) homologadas: Alto Rio Negro, Médio Rio Negro I, Médio Rio Negro II, Apapóris e Tea. A região compreende o município de São Gabriel da Cachoeira e trechos do município de Santa Isabel e o de Japurá, localizados no estado do Amazonas. Apesar dos quase dois séculos de contato com a população não-índia, seus habitantes são majoritariamente indígenas e permanecem identificando-se como tais. Estima-se que a população atual desses povos seja cerca de 30 mil pessoas distribuídas por 600 comunidades/aldeias.

Motivada pelo processo de luta pela demarcação das terras indígenas, em 1992 a Federação das Organizações Indígenas do Rio Negro (Foirn), realizou um levantamento censitário das comunidades e populações da região. O Censo Indígena Autônomo do Rio Negro (Ciarn) levantou informações populacionais de 314 comunidades e da cidade de São Gabriel da Cachoeira, contabilizando 16.897 pessoas.

Aqui, são analisados os tipos de casamentos contabilizados pelo Ciarn, procurando testar as hipóteses sobre a exogamia lingüística e a proximidade geográfica, formuladas pelos estudos etnológicos sobre essa região.

\section{Casamento no alto rio Negro}

Os trabalhos antropológicos sobre casamento enfocam as trocas matrimoniais enquanto sistemas operados por categorias sociais definidas no interior de cada sociedade. As escolhas matrimoniais dos cônjuges são feitas com base em um sistema de parentesco, em que a própria terminologia já determina os círculos de parentes consangüíneos e afins. Dado que o Ciarn não pesquisou o parentesco mais amplo entre os diferentes grupos domésticos e entre os habitantes de diferentes comunidades, ${ }^{2}$ inviabilizando um estudo aprofundado de trocas matrimoniais, o presente texto descreve apenas os tipos de casamentos contabilizados, buscando dialogar com algumas hipóteses formuladas pelas teorias antropológicas sobre a região, especificamente aquelas relacionadas a alguns princípios da estrutura social e da proximidade geográfica, e analisar as relações entre estes dois princípios, em cada sub-região estudada. 
Na região do alto rio Negro o grupo lingüístico é interpretado em termos nativos como um conjunto de parentes agnáticos descendentes de um grupo de irmãos ancestrais míticos, e é este grupo lingüístico que na região é interpretado como povo ou tribo. ${ }^{3}$ Para todas as etnias dessa região, o casamento, do ponto de vista do homem, deve ocorrer com sua prima cruzada bilateral ${ }^{4}$ (filha da irmã do seu pai ou do irmão de sua mãe), caracterizando-se assim por uma terminologia de parentesco do tipo dravidiano. A regra de descendência é patrilinear, vale dizer, o pertencimento ao grupo lingüístico ou etnia, e conseqüentemente ao sib e fratria, ocorre por intermédio do pai. O casamento deve ocorrer ainda entre unidades sociológicas exogâmicas, isto é, existe na região uma ideologia que prescreve o casamento fora de seu grupo de origem.

As unidades sociais exogâmicas variam de acordo com as famílias lingüísticas. Para todos os povos da região, a mulher depois de casada deve residir na comunidade do marido, obedecendo à regra de virilocalidade. Apenas entre os povos falantes de línguas maku (Hupdë, Yupdë e Dow, no lado brasileiro) o casamento deve ocorrer valendo-se de uma ideologia endogâmica; mas, neste caso, dentro de um mesmo grupo lingüístico, a saber, preferencialmente um homem hupdë deve casar com uma mulher hupdë, ou quando não houver mulheres para se casar no seu grupo deve procurar por uma que seja de outra etnia maku.

Para os Tukano ${ }^{5}$ o casamento preferencial se dá com sua prima cruzada bilateral e que preferencialmente resida em comunidades próximas. Muitos autores que estudaram os povos dessa região chamaram a atenção para as alianças matrimoniais que incluem, além das regras de parentesco e exogamia, princípios geográficos. Århem (1989), que trabalhou com os Makuna (grupo tukano), enfatiza o casamento como estruturador de relações sociais e políticas importantes, demonstrando que este grupo se casa com afins próximos e estabelece com eles relações de aliança política, econômica e ritual. Goldman (1963), que estudou os Kubeo, frisa, ainda, o ambiente social multilíngüe dessa região, definido pela regra de exogamia lingüística e pelo mito de origem dos grupos tukano, que permite a inclusão de diferentes povos falantes de línguas distintas, fato que constituiria, segundo esse autor, um ambiente "aberto". Cabalzar (1995, 2000), que trabalha na região com os Tuyuka (grupo tukano), chama a atenção para o fato de que o casamento deve também ocorrer entre comunidades próximas. Este autor tece considerações sobre o conceito de "nexos regionais", que seriam microrregiões formadas por diversos grupos locais (que geralmente coincidem com as comunidades) conectados por relações políticas, rituais e econômicas (Cabalzar, 2000). Analisando o espaço social das comunidades tuyuka, Cabalzar dialoga com os trabalhos de Århem (1989), que formula a idéia de "grupos de aliança local" e Goldman (1963) que postula a fratria como um ambiente mais amplo, onde se difundem os mecanismos de exogamia. Goldman (1963) descreve o casamento kubeo como o 
único caso de endogamia lingüística entre todos os grupos tukano, mas a prescrição de exogamia segue existindo, sendo para este povo uma ocorrência entre fratrias, que seriam, cada uma delas, um grupo de sibs originários de irmãos ancestrais. $\mathrm{O}$ caso kubeo coincidiria, portanto, com o caso dos Baniwa (povo aruak). Este autor chama atenção para o fato de que a regra geográfica define uma certa proibição de casar-se dentro de uma mesma comunidade, mesmo no caso de haverem mulheres elegíveis. Porém, o casamento deve sempre ocorrer entre comunidades próximas, e a geografia pode definir a identidade da fratria, ou seja, quando um grupo pertencente a uma determinada fratria se muda de região, pode não ser mais identificado como pertencente à fratria original.

Sobre a relação entre o princípio da proximidade geográfica de comunidades de afins, Chernela (1983) chama a atenção para os limitantes ecológicos como definidores de regiões onde se poderiam estabelecer e permanecer diversas comunidades, o que faria, segundo a autora, com que as regras de casamento também estivessem condicionadas a esses fatores ecológicos. Outra autora que enfatiza o princípio geográfico da proximidade do casamento é C. HughJones (1979), que trabalhou com os Barasana e afirma que, sendo as comunidades tukano ribeirinhas, os trechos de rio formariam nexos sociológicos de comunidades de afins. A autora pondera ainda que, possivelmente, os grupos periféricos, ou seja, aqueles cujas comunidades se localizam em regiões mais distantes do rio Uaupés, são mais instáveis, podendo a unidade local ou o grupo lingüístico não coincidirem com as unidades exogâmicas. Nesse caso, as unidades exogâmicas poderiam ser mais inclusivas, pois numa mesma região geográfica existiria uma diversidade maior de povos e sibs. Jackson (1984), em estudo sobre os Bará, discorre sobre seu modelo que inclui diferentes grupos lingüísticos ou etnias em uma mesma fratria. Essa autora afirma que um Bará não deve se casar com um Tukano, apesar de serem etnias diferentes, porque pertenceriam a uma mesma fratria. Seria, como diz C. Hugh-Jones (1979), uma unidade exogâmica composta. Outra autora que faz referência ao princípio da proximidade geográfica é Buchillet (1992), que observou a tendência entre os Desana do rio Papuri de estabelecerem laços matrimoniais com comunidades vizinhas.

Entre os Baniwa e Coripaco, povos de línguas aruak, o casamento deve ser exogâmico, isto é, além de um homem casar com sua prima cruzada bilateral, ele deve casar fora de seu grupo social. A unidade exogâmica, porém, não é, como no caso dos tukano, o grupo lingüístico, mas a fratria. Baniwa é uma denominação que define um grupo lingüístico, considerado povo ou tribo na região e englobando os Coripaco, falantes de uma língua semelhante, em um nível sociopolítico mais amplo; logo, sem definir uma unidade exogâmica. As fratrias baniwa (denominadas Hohodene, Dzawinai, Waliperi Dakenai etc.) identificam grupos descendentes de irmãos ancestrais comuns e são compostas por três ou mais sibs patrilineares. 
Esses sibs são ordenados hierarquicamente dentro de uma mesma fratria de acordo com a ordem de nascimento de seus irmãos ancestrais, da mesma maneira que para os tukano. O nome da fratria coincide com o nome do sib de mais alto grau na hierarquia, isto é, o grupo de indivíduos que descendem do irmão mais velho ancestral (Wright, 1981 e Buchillet, 1992)

As fratrias baniwa reconhecem um território comum, um trecho de rio onde as comunidades se localizam, e uma origem geográfica mítica comum; por exemplo, os Hohodene identificam a região da cachoeira do Uapuí, no alto rio Aiari, como seu lugar de origem. Esses trechos de rio são também compartilhados com as outras fratrias afins, vale dizer, comunidades de 'cunhados'.

Para os grupos falantes de línguas da família maku, cada grupo lingüístico divide-se em dois grupos patrilineares exogâmicos, não nomeados, e ligados entre si por laços de afinidade. E cada um desses grupos, por sua vez, subdividem-se em clâs patrilineares. Esses clãs encontram-se geograficamente dispersos em vários grupos locais, que são formados não por um grupo de irmãos como nas outras etnias, mas por grupos afins (Silverwood-Cope, 1990). Esses grupos locais são basicamente caçadores e coletores e habitam as cabeceiras e os intercursos dos rios e igarapés. Um grupo local em geral é constituído por um casal, cujo homem mais velho é a referência política do grupo, seus filhos solteiros e filhas casadas com seus esposos. O homem depois de casado, contrariamente aos outros grupos da região, deve residir temporariamente com seu sogro, obedecendo à regra de uxorilocalidade. Esses grupos locais são formados por vários grupos de fogos, ${ }^{6}$ unidos entre si por laços de afinidade, e sua composição não é estável, pode mudar por fusão com outro grupo local ou por fissão (Silverwood-Cope, 1990). Os povos maku são tradicionalmente endógamos, casam-se dentro de um mesmo grupo lingüístico ou com uma pessoa pertencente a uma outra etnia falante de língua maku.

De uma maneira geral, as comunidades dessa região do alto rio Negro são sempre localizadas nas margens dos rios ${ }^{7}$ e formadas por famílias conjugais (nucleares), chefiadas por membros do grupo local de descendência, geralmente pertencente a um mesmo sib de uma etnia. Por conseguinte, a comunidade é formada basicamente por homens irmãos casados, seus filhos e filhas solteiras. As mulheres vivem primeiramente com seus agnatas e depois do casamento vão morar com seus afins.

As comunidades geralmente trocam mulheres com outras comunidades identificadas localmente por "cunhados". ${ }^{8}$ O casamento de um filho homem é preferencialmente acompanhado pelo de uma filha mulher, ou seja, a comunidade da família que casa um filho homem recebe uma mulher (sua esposa), e, ao mesmo tempo, entrega uma filha mulher para aquela comunidade de "cunhados" que entregou uma esposa para seu filho. Sendo assim, o casamento de um filho é acompanhado pela perda de uma filha. Desse modo, o casamento se dá preferencialmente por "pares" (Lasmar, 2002). 
Isso posto, os casamentos representam tanto um processo de fissão da família conjugal original quanto um processo de estabelecimento de alianças com outras comunidades. Cabalzar (1995:45) relata que no mito de origem tuyuka,

a transformação da 'Cobra de Pedra' em seres humanos; tornam-se freqüentes as referências às separações entre os diferentes povos quie vieram do 'Lago do Leite', ao surgimento de línguas diferentes, e o que é mais importante, ao aparecimento da relação entre cunhados.

O casamento, portanto, representa uma força que pode desagregar o grupo de irmãos e agregar grupos de afins aliados políticos e rituais (Lasmar, 2002).

Nas análises feitas neste trabalho, são testadas as hipóteses da exogamia lingüística, para os Tukano, ${ }^{9}$ e da proximidade geográfica por trecho de rio e subregião. ${ }^{10}$ No caso dos povos baniwa e coripaco, não foi testada a hipótese de exogamia entre as diferentes fratrias, sendo apenas descritos os casamentos que ocorrem entre estes e outros povos ou internamente nestas mesmas etnias. São feitas análises por origem (nascimento) dos cônjuges e por sua residência no ano do Ciarn (1992). Para os povos de línguas maku não é feita distinção de etnia, pois estes estão identificados no Ciarn apenas como Maku, que é a maneira pela qual os Tukano identificam todas estas etnias. ${ }^{11}$ No caso dos Baré e Werekena, as duas outras etnias aruak, os casamentos também devem preferencialmente ocorrer dentro de seu próprio povo, sendo feita uma análise dos tipos de casamento por etnia e origem geográfica dos cônjuges.

Para efeito dessa pesquisa, a região do alto rio Negro foi dividida em cinco diferentes sub-regiões que foram delimitadas segundo critérios geográficos e sociológicos: Iauaretê, Tiquié/Uaupés, Içana, Negro Acima e Negro Abaixo.

A análise a seguir refere-se a 2.742 casais, distribuídos entre as subregiões conforme segue: 673 casais de Iauaretê; 565 do Tiquié/Uaupés; 587 do Içana; 375 do Negro Acima e 542 do Negro Abaixo. As comunidades de residência e de origem (nascimento) dos cônjuges foram classificadas conforme as sub-regiões e seus diferentes trechos de rios. As etnias são designadas por códigos que constam do Anexo I.

Será descrita a freqüência com que ocorrem as uniōes entre cônjuges de diferentes povos, ou seja, casos de exogamia lingüística, para as sub-regiões de Iauaretê e do Tiquié/Uaupés, prescrita para os povos tukano, tradicionais ocupantes dessas áreas. Para a região do Içana, de ocupação baniwa, são analisados os casamentos que ocorrem internamente à etnia e com outros povos. Nas subregiões do Negro Acima e Negro Abaixo, sendo a primeira de ocupação baré e werekena e a segunda de ocupação baré e região de destino de outros povos, são analisados os casamentos entre esses dois povos aruak, entre eles e os tukano, e entre os próprios tukano. 


\section{Mapa 1 - Sub-regiões no alto rio Negro}

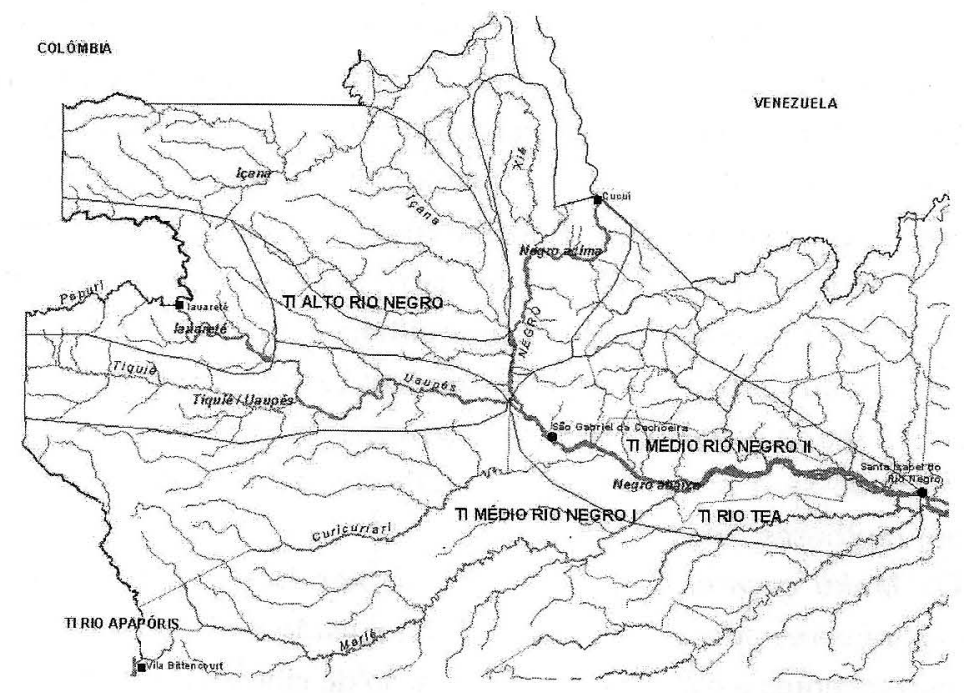

Para testar as hipóteses formuladas sobre o princípio da proximidade geográfica, as cinco sub-regiões foram subdivididas em trechos de rios ou centros missionários, conforme o Anexo II. Estes trechos de rios são contíguos e as microrregiões onde se localizam as comunidades que trocam cônjuges muitas vezes estão situadas nos limites entre os diferentes trechos de rios. Desta forma, nem todas as 'microrregiões de troca' ${ }^{12}$ foram delimitadas e demonstradas, seria preciso fazer estudos por comunidade e geo-referenciar as informações de casamento. Estão também identificados os países vizinhos, Colômbia e Venezuela, como lugares de origem dos cônjuges nascidos em comunidades vizinhas, dado que se trata de uma região de fronteira, ocupada por povos indígenas de áreas localizadas nestes dois países. Para identificar os cônjuges nascidos em sub-regiões distintas daquela estudada, utiliza-se o termo genérico 'fora'. Somente no caso das análises por origem geográfica da sub-região do Negro Abaixo são identificadas cada uma das outras sub-regiões como de origem dos cônjuges, por ser esta uma região de destino de migrações.

\section{Casamentos por etnia}

- Sub-região de Iauaretê

Iauaretê é habitada tradicionalmente pelos Tariana desde o trecho mais alto do rio Uaupés, até o começo do Papuri, encontrando-se ainda comunidades deste povo do médio rio Uaupés até a comunidade de Urubuquara. Os outros povos que ocupam a região e que estabelecem redes de trocas, das quais os casamentos fazem parte, são os Tukano, Piratapuia, Desana, Kubeo e outros falantes de línguas tukano. 
No momento da realização do Ciarn (1992), a maioria dos homens tariana estava casada com mulheres tukano; seguindo-se as uniões com mulheres piratapuia, além do pequeno número de uniões com mulheres de outros grupos tukano (Tabela 1). Chama-se a atenção para o fato de que os povos majoritários nas duas sub-regiões habitadas pelos tukano (Iauaretê e Tiquié/Uaupés) casam-se com mulheres pertencentes a um número maior de etnias. Porém, sempre ocorre uma preferência por duas ou três etnias, fato que fica demonstrado pelo elevado número de homens tariana casados com mulheres tukano ou piratapuia.

Os homens tukano, segunda etnia em tamanho nesta sub-região e uma das mais populosas da região do rio Negro, casam-se em maior número com mulheres tariana, seguindo-se a preferência por mulheres desana. A maioria dos Desana casa-se com mulheres tukano e wanana.

Os Maku casam-se entre si, confirmando a regra da preferência de casamento para estes povos. Os Kubeo também estão em sua maioria casados com mulheres pertencentes a esta etnia, com exceção de cinco homens que estão casados com mulheres wanana, povo que vive em comunidades próximas, e três casados com mulheres tariana e desana, sendo estas, provavelmente, habitantes de comunidades mais distantes geograficamente. A regra de casamento kubeo descrita por Goldman (1963) é observada nestes casos relatados.

Os casamentos endogâmicos não prescritos referem-se a cinco homens tariana casados com mulheres desta mesma etnia, e a cinco tukano e três wanana casados com mulheres consideradas parentes.

O esquema apresentado na Figura 1 procura descrever as trocas havidas entre etnias, sempre tomando como referência os homens. Deve-se ler da seguinte maneira: um homem tariana (TA) casa-se majoritariamente (flecha mais grossa em direção aos TU) com mulheres tukano, e em segundo lugar casa-se com mulheres piratapuia (flecha mais fina em direção aos PI). A direção da flecha neste esquema indica os homens indo se casar com mulheres das outras etnias. Pode-se notar que os Tariana são os que mais trocam mulheres, casando-se preferencialmente com os Tukano e Piratapuia, e 'doando' mulheres para muitos outros grupos diferentes. A Tabela 1 mostra que os Tariana são o povo que se casa com um maior número de etnias, seguidos dos Tukano. No caso dos Tariana, possivelmente se estabelecem as trocas duplas relatadas na literatura antropológica, pois tanto recebem mulheres tukano e piratapuia, quanto enviam mulheres tariana para estes povos.

Poderíamos dizer que, entre os povos tukano, os casamentos das etnias que tradicionalmente habitam uma determinada região serão formados por alianças com um número maior de etnias, estabelecendo relações sociais, políticas, econômicas e rituais com um maior número de comunidades. Os casamentos desta sub-região são quase todos exogâmicos, entre etnias diferentes, com exceção dos Maku e Kubeo, mas a exogamia lingüística é relativizada pela preferência por uma determinada 
proximidade geográfica, o que se comprova com o casamento de homens do Uaupés Acima com mulheres da região do Aiari ou Içana (Baniwa ou Coripaco).

Figura 1 - Trocas interétnicas em Iauaretê

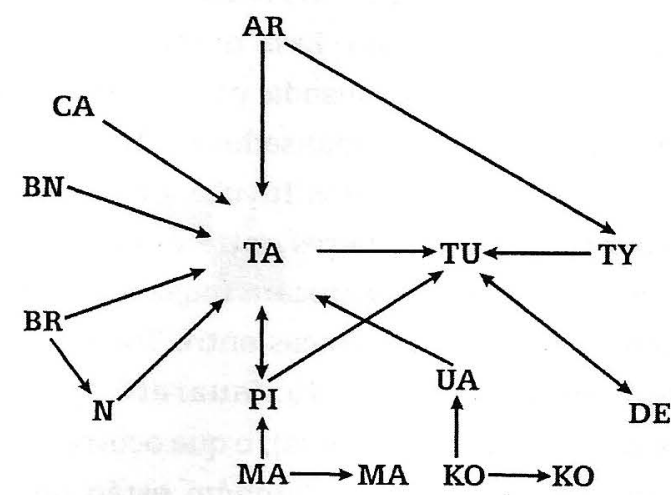

Tabela 1 - Casamentos por etnia, dos residentes na sub-região de Iauaretê

\begin{tabular}{|c|c|c|c|c|c|c|c|c|c|c|c|c|c|c|c|c|c|c|}
\hline \multirow[b]{2}{*}{ Homens } & \multicolumn{18}{|c|}{ Mulheres } \\
\hline & $\mathrm{AR}$ & BS & $\mathrm{BN}$ & $\mathrm{BR}$ & $\mathrm{CA}$ & $\mathrm{CO}$ & $\mathrm{DE}$ & JU & KO & MA & MI & $\mathrm{N}$ & PI & $\mathrm{TA}$ & $\mathrm{TU}$ & TY & UA & Total \\
\hline $\mathrm{AR}$ & - & - & - & - & - & - & 1 & - & - & - & - & - & - & 15 & 9 & - & - & 25 \\
\hline $\mathrm{BN}$ & - & - & - & - & - & - & - & - & - & - & - & - & - & 2 & - & - & - & 2 \\
\hline $\mathrm{BR}$ & - & - & - & - & - & - & - & - & - & - & - & 1 & - & 1 & - & - & - & 2 \\
\hline $\mathrm{CA}$ & - & - & - & - & - & - & - & - & - & - & - & - & - & 1 & - & - & - & 1 \\
\hline $\mathrm{DE}$ & 1 & - & - & 1 & - & - & - & 1 & - & - & - & - & 6 & 2 & 23 & - & 9 & 43 \\
\hline KO & - & - & 1 & - & - & 1 & 3 & - & 12 & - & - & - & - & 3 & - & 1 & 5 & 26 \\
\hline MA & - & - & - & - & - & - & - & - & - & 78 & - & - & 3 & & - & - & - & 81 \\
\hline$N$ & - & - & - & - & - & - & - & - & - & - & - & 1. & 1 & 5 & - & - & 1 & 8 \\
\hline PI & - & - & - & - & - & - & 16 & 1 & 1 & 2 & - & - & - & 32 & 18 & - & 2 & 72 \\
\hline $\mathrm{TA}$ & 10 & 1 & 2 & 4 & 2 & - & 5 & 1 & 5 & - & 1 & 1 & 59 & 5 & 83 & 3 & 14 & 196 \\
\hline $\mathrm{TU}$ & 8 & 1 & - & - & 1 & - & 30 & 1 & - & 3 & - & - & 15 & 57 & 5 & 12 & 7 & 140 \\
\hline TY & - & 1 & - & - & - & - & 1 & - & - & - & - & - & - & 1 & 9 & - & - & 12 \\
\hline UA & 1 & - & 6 & 1 & 1 & 1 & 12 & - & 9 & - & - & - & - & 20 & 8 & 3 & 3 & 65 \\
\hline Total & 20 & 3 & 9 & 6 & 4 & 2 & 68 & 4 & 27 & 83 & 1 & 3 & 84 & 144 & 155 & 19 & 41 & 673 \\
\hline
\end{tabular}

Fonte: Ciarn. 
- Sub-região do Tiquié/Uaupés

Esta sub-região é habitada majoritariamente pelos Tukano, Desana e Tuyuka. No momento de realização do Ciarn, os Tukano da região estavam casados, em sua maioria, com mulheres desana, seguindo-se as mulheres tuyuka, principalmente no trecho do alto rio Tiquié. Os casamentos tuyuka também ocorrem em maior número com mulheres tukano. Essa grande freqüência de casamentos tuy̌ka com tukano foi largamente analisada por Cabalzar (2000), conforme já mencionado anteriormente, e os dados analisados na Tabela 2 vêm confirmar que os Tukano são os cunhados preferenciais dos Tuyuka, pelo menos do lado brasileiro. A Figura 2 representa as trocas de mulheres entre os diferentes povos desta subregião, e mostra que as duas etnias que trocam majoritariamente mulheres entre si são Tukano e Desana, seguidas pelas trocas entre Tuyuka e Tukano.

Assim como na sub-região de Iauaretê, os Desana casam-se majoritariamente com os Tukano (e vice-versa), o que ocorre também na sub-região do Negro Abaixo, onde estes dois povos também estão presentes. Os Tariana, presentes em número pequeno nesta sub-região, aqui também se casam com mulheres tukano e piratapuia, repetindo o tipo de casamento encontrado em Iauaretê.

Os Maku, habitantes tradicionais dos intercursos dos rios e de comunidades situadas em igarapés afluentes do Tiquié, estão representados por 114 homens e 116 mulheres. Entre os homens, apenas um está casado com uma mulher tukano, e entre as mulheres, somente três casaram-se com homens desana. Assim como na sub-região de Iauaretê, no Tiquié/Uaupés também se confirma a regra de casamento preferencial dos Maku com povos falantes desta família lingüística.

Os únicos casos de endogamia lingüística tukano, ou seja, de uniões consideradas incestuosas pela regra tradicional, são os de 14 homens casados com mulheres tukano, três homens desana casados com mulheres desana e 1 homem mirititapuia casado com uma mulher da mesma etnia.

No esquema (Figura 2), as possíveis trocas duplas se dão entre os Tukano e Desana, os Tuyuka e Tukano e os Desana e Tukano. Existe também um pequeno número de trocas entre os Tuyuka e Desana. Estes casamentos podem ser considerados como geograficamente próximos, visto que estas etnias estão localizadas, principalmente, em comunidades do Tiquié. 
Tabela 2 - Casamentos por etnia, dos residentes na sub-região do Tiquié/Uaupés.

\begin{tabular}{|c|c|c|c|c|c|c|c|c|c|c|c|c|c|c|c|c|c|c|}
\hline \multirow[b]{2}{*}{ Homens } & \multicolumn{18}{|c|}{ Mulheres } \\
\hline & AR & $\mathrm{BN}$ & BR & BS & CA & $\mathrm{CO}$ & $\mathrm{DE}$ & KO & MA & MI & MK & $\mathrm{N}$ & PI & TA & $\mathrm{TU}$ & TY & UA & Total \\
\hline $\mathrm{AR}$ & - & - & - & - & - & - & 1 & - & - & - & - & - & - & - & 1 & - & - & 2 \\
\hline BA & - & - & - & - & - & - & 2 & - & - & - & - & - & - & - & 1 & - & - & 3 \\
\hline BR & - & 1 & - & - & - & - & 1 & - & - & - & - & - & - & - & 1 & - & - & 3 \\
\hline BS & - & - & - & - & - & - & - & - & - & - & - & - & - & - & - & 1 & - & 1 \\
\hline $\mathrm{CA}$ & - & - & - & - & - & - & 2 & - & - & - & - & - & - & - & - & - & - & 2 \\
\hline $\mathrm{DE}$ & 2 & - & - & - & - & - & 3 & - & 3 & 5 & 2 & - & 5 & 2 & 77 & 10 & - & 109 \\
\hline MA & - & - & - & - & - & - & - & - & 113 & - & - & - & - & - & 1 & - & - & 114 \\
\hline MI & - & - & - & - & 1 & - & 2 & - & - & 1 & - & - & - & 1 & 12 & 2 & - & 19 \\
\hline MK & - & - & - & - & - & - & 1 & - & - & - & $\overline{5}$ & - & - & - & - & 4 & - & 5 \\
\hline $\mathrm{N}$ & - & - & - & - & - & - & 1 & - & - & - & - & - & 1 & - & 1 & - & - & 3 \\
\hline PI & & 1 & & & & & 5 & & & & & & - & 5 & 13 & & & 24 \\
\hline $\mathrm{TA}$ & 2 & - & - & - & - & 1 & 3 & - & - & - & - & - & 4 & - & 6 & 3 & 2 & 21 \\
\hline TU & 3 & 1 & 1 & - & - & - & 76 & 1 & 2 & 8 & - & 1 & 15 & 21 & 14 & 59 & 2 & 204 \\
\hline TY & - & - & - & 6 & - & - & 5 & - & 3 & 2 & 2 & - & 2 & - & 35 & - & - & 55 \\
\hline Total & 7 & 3 & 1 & 6 & 1 & 1 & 102 & 1 & 121 & 16 & 4 & 1 & 27 & 29 & 162 & 79 & 4 & 565 \\
\hline
\end{tabular}

endogamia considerada incesto endogamia permitida

Fonte: Ciarn.

Figura 2 - Trocas matrimoniais entre etnias na sub-região do Tiquié/ Uaupés.

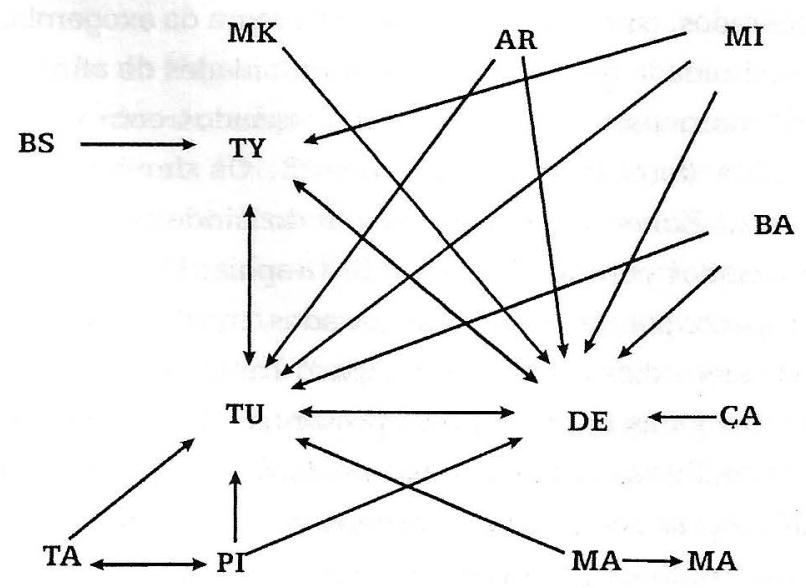


De uma maneira geral, nestas duas sub-regiões analisadas, onde tradicionalmente vivem os povos tukano, a exogamia lingüística é estritamente observada, ocorrendo poucos casos de endogamia não permitida. Observa-se ainda que cada povo tem um maior número de ocorrências de casamentos com alguns outros povos, o que se demonstra nos esquemas quando as flechas estão nas duas direções. Podemos concluir, ainda, que as etnias majoritárias em termos de tamanho de população, que habitam tradicionalmente cada uma destas duas sub-regiões, casam-se com um maior número de diferentes etnias, ampliando assim seu leque de alianças políticas, econômicas e rituais.

É interessante notar que nessas duas sub-regiões, Iauaretê e Tiquié/ Uaupés, o casamento entre etnias que se consideram 'parentes' ou como pertencendo a uma grande fratria (Jackson, 1984) ou como unidades exogâmicas compostas (Hugh-Jones, 1979) não ocorre de maneira expressiva.

- Sub-região do Içana

Trata-se da região onde estão localizadas as comunidades baniwa, que se estendem pelos rios Içana, Aiari, Cuiari e também estão presentes na sub-região do Negro Abaixo, tendo migrado até às cidades de Santa Isabel e Barcelos.

Os povos baniwa e coripaco são os mais populosos dessa região do alto rio Negro, estando presentes também na Colômbia e Venezuela. Os Coripaco habitam as comunidades do alto rio Içana, e predominam na Colômbia. Falam uma língua muito semelhante ao Baniwa, com algumas variações dialetais. O casamento desses dois povos deve ocorrer no interior das etnias, sendo a exogamia prescrita no nível das fratrias, segundo já foi explicado antes. Os Baniwa casam-se também com os Kubeo e Wanana, em virtude da proximidade geográfica de suas comunidades localizadas no trecho do rio Uaupés acima de Iauaretê. Conforme já mencionado, esses casamentos, ainda que não esperados, caso se conside apenas a regra da exogamia, acontecem pela preferência da proximidade geográfica entre comunidades de afins.

Dos 444 homens baniwa, 388 estão casados com mulheres da mesma etnia, conforme fica demonstrado na Tabela 3. Os demais estão casados com Coripaco, Werekena, Kubeo e Wanana, restando ainda um pequeno número de homens baniwa casados com as Tariana, Mirititapuia, Desana, Arapaso, Tukano e não-índio. Os Coripaco, por sua vez, estão casados, maciçamente, com mulheres da mesma etnia. Há, além disso, homens coripaco casados com mulheres baniwa, e vice-versa. Os homens das demais etnias presentes na sub-região são casados em grande parte com mulheres baniwa, salvo os Baré, majoritariamente casados com mulheres de sua própria etnia. Os 20 homens werekena presentes na sub-região, estão casados com mulheres baniwa, possibilitando dessa maneira a criação de uma rede de relações de troca com a etnia majoritária desta sub-região. 
Como nas duas sub-regiões anteriores, são os Baniwa que se casam com um maior número de etnias, 10 etnias distintas, excluindo-se eles próprios e os não-índios. Os Coripaco, outro povo tradicional desta sub-região, casam-se apenas entre si ou com os Baniwa, encontrando-se apenas um homem coripaco que está casado com uma mulher kubeo.

Tabela 3 - Casamentos por etnia, dos residentes na sub-região do Içana

\begin{tabular}{|c|c|c|c|c|c|c|c|c|c|c|c|c|c|}
\hline \multirow[b]{2}{*}{ Homens } & \multicolumn{13}{|c|}{ Mulheres } \\
\hline & AR & $\mathrm{BN}$ & BR & $\mathrm{CO}$ & $\mathrm{DE}$ & KO & MI & $\mathrm{N}$ & TA & TU & UA & EU & Total \\
\hline $\mathrm{BN}$ & 1 & 388 & 8 & 16 & 1 & 10 & 2 & 1 & 7 & 1 & 8 & 13 & 456 \\
\hline $\mathrm{BR}$ & - & 6 & 7 & 1 & - & - & - & - & 1 & - & - & 3 & 18 \\
\hline $\mathrm{CA}$ & - & 1 & - & - & - & - & - & - & - & - & - & - & 1 \\
\hline $\mathrm{CO}$ & - & 16 & - & 43 & - & 1 & - & - & - & - & - & - & 60 \\
\hline $\mathrm{DE}$ & - & 4 & - & - & - & - & - & - & - & 1 & 2 & - & 7 \\
\hline KO & - & 3 & - & 1 & - & 1 & - & - & - & - & - & - & 5 \\
\hline $\mathrm{N}$ & - & - & - & 1 & 1 & - & - & - & - & - & - & - & 2 \\
\hline $\mathrm{TA}$ & - & 3 & 1 & - & - & - & - & - & - & - & - & 3 & 7 \\
\hline TU & - & 4 & - & - & - & - & - & - & - & - & 1 & - & 5 \\
\hline TY & - & 1 & - & - & - & - & - & - & - & 1 & - & - & 2 \\
\hline UA & - & 3 & - & - & - & - & - & - & - & 1 & - & - & 4 \\
\hline UE & - & 15 & 1 & - & - & 1 & - & - & 2 & - & - & 1 & 20 \\
\hline Total & 1 & 444 & 17 & 62 & 2 & 13 & 2 & 1 & 10 & 4 & 11 & 20 & 587 \\
\hline
\end{tabular}

endogamia considerada incesto

endogamia permitida

Fonte: Ciarn.

- Sub-região do Negro Acima

As comunidades situadas nas margens do rio Negro, desde a fronteira com a Venezuela até a região da Ilha das Flores, cerca da foz do Uaupés, são em sua maioria habitadas pelos Baré. Essa sub-região é a única dentre as estudadas que possui um trecho do rio Negro (que vai desde a comunidade de Vista Alegre, até a fronteira com a Venezuela) fora das terras indígenas demarcadas (margem esquerda do rio Negro, ver Mapa 1). Os Baré tradicionalmente falavam uma língua aruak, que foi paulatinamente sendo substituída pelo nheengatu, língua geral introduzida pelos missionários e falada também pelos Werekena, que mantêm sua língua original.

Por ocasião da realização do Ciarn, os Baré estavam majoritariamente casados entre si (Tabela 4), seguindo-se os casamentos com mulheres werekena na região do baixo rio Xié, e com mulheres baniwa, na região do baixo Içana. Os homens werekena estavam majoritariamente casados com mulheres da mesma 
etnia, seguindo-se as uniões com os Baré e os Baniwa. Portanto, nesta sub-região, os casamentos também ocorrem de acordo com a prescrição, vale dizer, os dois povos majoritários preferencialmente devem se casar com mulheres falantes da mesma língua. Os Baniwa aí residentes seguem a mesma tendência de casamento observada na sua sub-região de ocupação tradicional, casando-se preferencialmente entre si.

Vale notar que, como ocorre nas outras três sub-regiões, a etnia predominante nesta região - os Baré - é a que se casa com um maior número de povos distintos.

Tabela 4 - Casamentos por etnia, dos residentes na sub-região do Negro Acima

\begin{tabular}{ccccccccccccc}
\hline & \multicolumn{10}{c}{ Mulheres } \\
\cline { 2 - 12 } Homens & AR & BN & BR & CO & DE & PI & TA & TU & TY & UA & EU & Total \\
\hline AR & - & - & - & - & 2 & 1 & 2 & 4 & - & - & - & 9 \\
BN & - & 18 & 12 & 1 & - & - & 2 & 2 & - & - & 6 & 41 \\
BR & 1 & 16 & 185 & 3 & 1 & - & - & 5 & - & 1 & 18 & 230 \\
CO & - & 2 & 1 & - & - & - & - & 1 & - & - & - & 4 \\
DE & - & - & 1 & - & - & 1 & - & 3 & - & - & - & 5 \\
N & - & 1 & 10 & - & - & - & 1 & - & - & - & - & 12 \\
PI & - & - & 2 & - & 1 & - & - & 1 & - & - & - & 4 \\
TA & 1 & 2 & 2 & - & - & 1 & - & 1 & - & - & 1 & 8 \\
TU & 2 & 1 & - & - & - & 1 & 2 & 2 & 1 & - & 3 & 12 \\
TY & - & 1 & - & - & - & - & - & - & - & - & - & 1 \\
UE & 1 & 8 & 8 & 1 & - & - & 1 & 2 & - & - & 28 & 49 \\
\hline Total & 5 & 49 & 221 & 5 & 4 & 4 & 8 & 21 & 1 & 1 & 56 & 375 \\
\hline
\end{tabular}

endogamia considerada incesto endogamia permitida

Fonte: Ciarn.

\section{- Sub-região do Negro Abaixo}

Esta sub-região é onde se localiza a cidade de São Gabriel da Cachoeira, sede do município, e região de destino de migração de muitas famílias indígenas, sejam tukano, ou aruak. Assim como a sub-região do Negro Acima é área de ocupação tradicional dos Baré, etnia ainda preponderante, por mais que exista um número expressivo de índios de outras etnias vivendo em comunidades desta subregião, e na cidade de São Gabriel da Cachoeira.

Os Baré desta região estavam casados na sua maioria com mulheres deste mesmo povo (Tabela 5); todavia, diferentemente do que ocorre na sub-região do Negro Acima, os homens baré se casam em segundo lugar com mulheres tukano e desana (e não com Werekena), estabelecendo alianças com mulheres oriundas das 
famílias destes povos que migraram para esta região. Os Tukano estão casados majoritariamente com mulheres desana, assim como já visto na sub-região do Tiquié/Uaupés. Este casamento também é muito expressivo em Iauaretê, apenas antecedido pelo casamento de homens tukano com mulheres tariana. Os Tariana também seguem o mesmo tipo de preferência de casamento de sua região tradicional, isto é, com mulheres tukano ou piratapuia, além de ocorrerem casamentos com outros grupos, incluindo seis casos de casamentos com Arapaso, situação igualmente observada em Iauaretê. Nesse sentido, é possível supor que os Tukano, que não são originários desta sub-região, tenham se casado antes de migrar ou continuem obedecendo às mesmas regras de preferência de casamento. A regra da exogamia lingüística parece permanecer operante, apesar de existir um número maior de homens tukano casados com mulheres desta mesma etnia.

Da mesma forma que nas outras quatro sub-regióes estudadas, a etnia prevalecente é que se casa com um maior número de povos distintos. Neste caso são os Baré, que estão casados com 12 povos diferentes, excluindo-se os não-índios.

Tabela 5 - Casamentos por etnia, dos residentes na sub-região do Negro Abaixo

\begin{tabular}{|c|c|c|c|c|c|c|c|c|c|c|c|c|c|c|c|c|c|}
\hline \multirow[b]{2}{*}{ Homens } & \multicolumn{17}{|c|}{ Mulheres } \\
\hline & $\mathrm{AR}$ & $\mathrm{BN}$ & $\mathrm{BR}$ & $\mathrm{CA}$ & $\mathrm{CO}$ & $\mathrm{DE}$ & KO & MA & MI & $\mathrm{N}$ & PI & $\mathrm{TA}$ & TU & TY & UA & $\mathrm{UE}$ & Total \\
\hline AR & - & 1 & - & - & - & 2 & - & - & - & - & - & 1 & 3 & - & - & - & 7 \\
\hline $\mathrm{BN}$ & 2 & 37 & 5 & - & 1 & 4 & 1 & - & - & - & - & 1 & 2 & 1 & - & - & 54 \\
\hline $\mathrm{BR}$ & 1 & 8 & 99 & 1 & 1 & 17 & 2 & - & - & 3 & 5 & 8 & 30 & 1 & 2 & - & 178 \\
\hline $\mathrm{CA}$ & - & - & - & - & - & 1 & - & - & - & - & - & - & - & - & - & - & 1 \\
\hline $\mathrm{DE}$ & 1 & 10 & 7 & - & - & 1 & - & 1 & - & 1 & 11 & 7 & 34 & 1 & - & 1 & 75 \\
\hline $\mathrm{JU}$ & - & - & - & 1 & - & - & - & - & - & - & - & - & - & - & - & - & 1 \\
\hline KO & - & - & - & - & - & 1 & - & - & - & - & - & - & - & - & - & - & 1 \\
\hline MA & - & - & - & - & - & - & - & 15 & - & - & - & - & - & - & - & - & 15 \\
\hline $\mathrm{N}$ & 2 & 2 & 3 & - & - & - & - & - & - & 2 & - & - & 2 & 1 & - & - & 12 \\
\hline PI & 1 & 2 & 2 & - & - & 5 & - & - & - & - & 3 & 9 & 12 & 1 & - & - & 35 \\
\hline TA & 6 & 2 & 4 & - & - & 3 & - & - & - & 1 & 6 & 3 & 11 & 1 & - & - & 37 \\
\hline $\mathrm{TU}$ & 7 & 8 & 6 & 2 & - & 23 & - & 2 & 2 & - & 18 & 21 & 22 & 2 & - & - & 113 \\
\hline TY & - & - & - & - & - & 2 & - & - & - & - & - & - & 4 & - & - & - & 6 \\
\hline UA & - & 3 & 1 & - & - & 2 & - & - & - & - & - & - & 1 & - & - & - & 7 \\
\hline Total & 20 & 73 & 127 & 4 & 2 & 61 & 3 & 18 & 2 & 7 & 43 & 50 & 121 & 8 & 2 & 1 & 542 \\
\hline
\end{tabular}

endogamia considerada incesto endogamia permitida

Fonte: Ciarn. 


\section{Casamentos por microrregiões}

- Sub-região de Iauaretê

Os 673 casais da sub-região estão distribuídos por trecho de rio de nascimento, denominado por origem geográfica (Tabela 6). A maior parte dos 611 homens que reside nesta sub-região é originária da área. As mulheres nascidas na Colômbia ou fora, residentes na sub-região, são mais numerosas do que os homens dessas localidades. A maioria é originária da sub-região de Iauaretê. Na Tabela 6 é possível observar que a maior parte dos homens originários dos trechos de rios desta sub-região está casada com mulheres desses mesmos trechos de rio. A única exceção é em Iauaretê Centro, onde a maior parte dos homens está casada com mulheres do Papuri.

Esse tipo de análise possibilitou também avaliar a proporção de homens e mulheres que após o casamento continuam na sub-região de residência. No trecho de rio do Uaupés, $75 \%$ dos homens e $58 \%$ das mulheres permanecem na região onde residiam antes do casamento. Estas proporções variam por trecho de rio; contudo, a tendência se mantém favorável ao sexo masculino. A foz deste rio no Uaupés possivelmente forma outra microrregião de trocas matrimoniais, que se sobrepõe ao trecho de rio Uaupés. A existência de casamentos fora das microrregiões de troca indica que elas se sobrepõem. A Colômbia pode ser considerada no caso dos trechos dos rios Uaupés Acima e Papuri como parte das microrregiões de troca, uma vez que a margem direita do Uaupés e a esquerda do Papuri, já neste país, são ocupadas por comunidades que fazem parte das redes de trocas com as comunidades localizadas do lado brasileiro.

Tabela 6 - Sub-região de Iauaretê - casamentos por origem geográfica dos cônjuges

\begin{tabular}{cccccccc}
\hline & \multicolumn{7}{c}{ Mulheres } \\
\cline { 2 - 8 } Homens & $\begin{array}{c}\text { Iauareté } \\
\text { Centro }\end{array}$ & Uaupés & $\begin{array}{c}\text { Uaupés } \\
\text { Acima }\end{array}$ & Colômbia & Papuri & fora & Total \\
\hline $\begin{array}{c}\text { Iauareté } \\
\text { Centro }\end{array}$ & 8 & 15 & 15 & 7 & 16 & 6 & 67 \\
Uaupés & 14 & 80 & 14 & 12 & 35 & 21 & 176 \\
$\begin{array}{c}\text { Uaupés } \\
\text { Acima }\end{array}$ & 6 & 12 & 67 & 23 & 30 & 29 & 167 \\
Colômbia & 2 & 2 & 3 & 6 & 3 & 1 & 17 \\
Papuri & 14 & 29 & 20 & 36 & 86 & 16 & 201 \\
fora & 2 & 11 & 3 & 3 & 12 & 14 & 45 \\
\hline Total & 46 & 149 & 122 & 87 & 182 & 87 & 673 \\
\hline
\end{tabular}

casamento fora da microrregião casamento dentro da microrregião

Fonte: Ciarn. 
O caso dos três centros missionários e da área urbana de São Gabriel da Cachoeira é distinto dos diferentes trechos de rios. Os casamentos contabilizados pelo Ciarn, em 1992, estavam organizados de maneira a continuar com os mesmos tipos de trocas entre as diferentes etnias, mantendo-se a diferença entre a proporção de homens que nascem e ficam nestes centros missionários/urbanos e mulheres que se casam e acabam se mudando de lugar. Situação análoga foi observada por Jackson (1984) em seu trabalho sobre os Bará, indivíduos originários de centros missionários, por serem locais de migração de famílias oriundas de distintas comunidades, não mantinham a preferência pela proximidade geográfica de casamento. Iauaretê Centro é originário de uma missão salesiana, instalada em uma área de ocupação tradicional dos Tariana, onde duas grandes aldeias deste povo existiam, e ainda se mantêm como bairros deste povoado.

- Sub-região do Tiquié/Uaupés

Nesta sub-região residem 565 casais, distribuídos por três trechos de rios e dois povoados. A maior parte dos homens é nascida na sub-região, e os restantes são 53 homens nascidos em outras sub-regiões, e sete homens nascidos em comunidades vizinhas na Colômbia.

Na Tabela 7, é possível verificar que os homens nascidos no Alto Tiquié e Pari Cachoeira Centro são casados majoritariamente com mulheres deste mesmo trecho de rio. Nos outros dois trechos de rio, Baixo Tiquié e Uaupés, os homens se casam com mulheres do Alto Tiquié e de fora, respectivamente. Na Tabela 7, estão marcados com cinza os casamentos próximos e com preto os que podem ser considerados casamentos distantes.

Tabela 7 - Sub-região do Tiquié/Uaupés - casamentos de residentes por origem geográfica dos cônjuges

\begin{tabular}{ccccccccc}
\hline & \multicolumn{7}{c}{ Mulheres } \\
\cline { 2 - 9 } Homens & $(1)$ & $(2)$ & $(3)$ & $(4)$ & $(5)$ & $(6)$ & $(7)$ & Total \\
\hline Uaupés (1) & 15 & 1 & 11 & 5 & 2 & 26 & 2 & 62 \\
Baixo Tiquié (2) & 2 & 13 & 21 & 1 & 1 & 3 & 2 & 43 \\
Alto Tiquié (3) & 8 & 17 & 244 & 27 & 2 & 25 & 15 & 338 \\
Pari Cachoeira Centro (4) & 2 & - & 27 & 6 & - & 5 & 1 & 41 \\
Taracuá Centro (5) & 4 & 4 & 3 & 1 & 1 & 6 & 2 & 21 \\
fora (6) & 9 & 4 & 16 & 2 & 3 & 18 & 1 & 53 \\
Colômbia (7) & - & - & 3 & - & - & 1 & 3 & 7 \\
\hline Total & 40 & 39 & 325 & 42 & 9 & 84 & 26 & 565 \\
\hline
\end{tabular}

casamento fora da microrregião

casamento dentro da microrregião

Fonte: Ciarn. 
Em todos os trechos de rios do Tiquié e do Uaupés os homens permanecem residindo na sua microrregião de origem em uma proporção de aproximadamente 80 a $90 \%$; as mulheres numa proporção de cerca de $50 \%$.

- Sub-região do Içana

Esta sub-região é tradicionalmente ocupada pelos povos baniwa e coripaco, e no baixo rio Içana existem ainda algumas comunidades baré. A maior parte dos homens e mulheres aí nascidos continua a residir nesta mesma sub-região após o casamento. Entre os homens e mulheres não-naturais dessa sub-região, a maioria vem de outras sub-regiões do Brasil, e uma pequena parcela vem da Colômbia e Venezuela. Pode-se observar, na Tabela 8, que os homens naturais dos três trechos de rios desta sub-região estão casados com mulheres naturais destas mesmas microrregiões; somente o centro missionário de Assunção é que foge à regra.

Da mesma forma que nas outras duas sub-regiões anteriormente analisadas, os homens permanecem em proporção de quase $90 \%$ no seu trecho de rio de origem, e as mulheres permanecem em uma proporção de cerca de $50 \%$. Em Assunção do Içana, centro missionário de formação mais recente do que Iauaretê e Pari Cachoeira, os casais estudados são em sua maioria naturais do baixo Içana e Aiari; nesse caso, também os homens originários desse centro permanecem na sub-região em proporção maior do que as mulheres.

Tabela 8 - Sub-região do Içana - casamentos dos residentes por origem geográfica dos cônjuges

\begin{tabular}{cccccccccc}
\hline & \multicolumn{7}{c}{ Mulheres } \\
\cline { 2 - 9 } Homens & $(1)$ & $(2)$ & $(3)$ & $(4)$ & $(5)$ & $(6)$ & $(7)$ & Total \\
\hline Assunção Centro (1) & 1 & 2 & 1 & - & 1 & - & - & 5 \\
Aiari (2) & 6 & 90 & 9 & 37 & 14 & 4 & - & 160 \\
Baixo Içana (3) & 4 & 10 & 125 & 14 & 20 & 1 & - & 174 \\
Alto Içana (4) & 1 & 27 & 14 & 142 & 4 & 5 & 1 & 194 \\
fora (5) & 4 & 9 & 14 & 7 & 6 & 1 & - & 41 \\
Colômbia (6) & - & 1 & 3 & 7 & 1 & - & - & 12 \\
Venezuela (7) & - & 1 & - & - & - & - & - & 1 \\
\hline Total & 16 & 140 & 166 & 207 & 46 & 11 & 1 & 587 \\
\hline
\end{tabular}

- casamento fora da microrregião casamento dentro da microrregião Fonte: Ciarn. 
- Sub-região do Negro Acima

Esta sub-região é tradicionalmente ocupada pelos Baré e Werekena, existindo também comunidades baniwa na foz do rio Içana. A maior parte dos homens e mulheres naturais desta sub-região continua na mesma área após o casamento. Pode-se constatar que os homens naturais desse trecho do rio Negro e do rio Xié estão casados com mulheres naturais das mesmas microrregiões.

Tabela 9 - Sub-região do Negro Acima - casamentos dos residentes por oriģem cleográfica dos cônjuges

\begin{tabular}{cccccccc}
\hline & \multicolumn{7}{c}{ Mulheres } \\
\cline { 2 - 8 } Homens & $(1)$ & $(2)$ & $(3)$ & $(4)$ & $(5)$ & $(6)$ & Total \\
\hline Negro (1) & 118 & 1 & 5 & 31 & 2 & 1 & 158 \\
Cucuí (2) & 16 & 13 & - & 6 & 1 & - & 36 \\
Xié (3) & 3 & - & 57 & 15 & 1 & - & 76 \\
fora (4) & 22 & 4 & 11 & 56 & 1 & 1 & 95 \\
Colômbia (5) & - & - & 2 & 5 & - & - & 7 \\
Venezuela (6) & 1 & - & 2 & - & - & - & 3 \\
\hline Total & 160 & 18 & 77 & 113 & 5 & 2 & 375 \\
\hline
\end{tabular}

casamento fora da microrregião casamento dentro da microrregião Fonte: Ciarn.

Tanto no rio Xié, quanto nesse trecho do rio Negro, após o casamento, os homens e mulheres permanecem residindo em suas microrregiões de origem em proporções quase iguais, o que é um pouco diferente do que ocorre nas outras sub-regiões.

Cucuí é um pequeno centro urbano localizado no trecho do rio Negro desta sub-região do Negro Acima. Faz fronteira com a Venezuela e Colômbia, e possui uma escola de ensino fundamental, e um pelotão de fronteira do exército. O povoado se originou de uma comunidade baré, população majoritária deste centro urbano ainda atualmente. De todos os homens e mulheres naturais deste centro urbano (36 e 18, respectivamente) todas as mulheres e 35 homens permanecem neste mesmo local. Este é o único caso em que não foi possível observar a tendência da maior permanência dos homens. Dos 35 homens naturais e residentes em Cucuí, 15 deles estão casados com mulheres do Negro, 13 com mulheres de Cucuí mesmo, e seis com mulheres de fora; apenas um homem está casado com uma mulher da Colômbia. 
- Sub-região do Negro Abaixo

Esta sub-região é tradicionalmente ocupada pelos Baré e é onde está localizada a cidade de São Gabriel da Cachoeira, sede do município. Esta sub-região vem recebendo há muitos anos famílias indígenas oriundas de outras sub-regiões, e já em 1992, ano do Ciarn, existiam vários bairros indígenas na cidade. No trecho do rio Negro que vai desde São Gabriel até Santa Isabel existem muitas comunidades ocupadas por famílias tukano. As análises feitas desta sub-região se diferenciam das outras: nos outros casos as pessoas nascidas em sub-regiões distintas daquelas estudadas estão classificadas como originárias de 'fora'. Nesta sub-região as pessoas foram classificadas por sub-região de origem, para dar uma idéia melhor da composição dos adultos por origem geográfica, dado que se trata de uma região de destino de migração. As pessoas classificadas como naturais de 'fora' na Tabela 10 são procedentes de outros municípios, sobretudo de Barcelos.

São 542 casais aí residentes; destes, 292 são homens naturais desta sub-região e 250 naturais de outras áreas, incluindo Colômbia, Venezuela e fora. Das outras quatro sub-regiões estudadas, é de Iauaretê que se origina o maior número de homens aí residentes, seguida pelas sub-regiões do Tiquié/Uaupés, Negro Acima e Içana.

Os homens naturais do trecho do rio Negro residentes nesta sub-região estão casados com mulheres naturais desta mesma microrregião (Tabela 10). Dentre os homens naturais e residentes em São Gabriel da Cachoeira, a maioria está casada com mulheres desta cidade, o que não é o padrão observado nos outros centros urbanos.

Tabela 10 - Sub-região do Negro Abaixo - casamentos dos residentes por origem geográfica dos cônjuges

\begin{tabular}{ccccccccc}
\hline & \multicolumn{7}{c}{ Mulheres } \\
\cline { 2 - 9 } Homens & $(1)$ & $(2)$ & $(3)$ & $(4)$ & $(5)$ & $(6)$ & $(7)$ & Total \\
\hline Săo Gabriel (1) & 16 & 8 & 6 & - & 4 & 2 & - & 36 \\
Negro (2) & 8 & 165 & 22 & 23 & 24 & 11 & 3 & 256 \\
Iauareté (3) & 2 & 19 & 38 & 3 & 21 & 4 & 3 & 90 \\
Içana (4) & 1 & 9 & 2 & 27 & 1 & - & - & 40 \\
Tiquié/Uaupés (5) & 2 & 12 & 14 & 1 & 32 & 2 & - & 63 \\
Negro Acima (6) & 7 & 4 & 2 & 5 & 5 & 28 & - & 45 \\
Colômbia (7) & - & 1 & - & 1 & 1 & 1 & 1 & 5 \\
Venezuela (8) & - & 1 & - & - & - & - & - & 1 \\
fora (9) & - & 4 & 1 & - & 1 & - & - & 6 \\
\hline Total & 36 & 223 & 85 & 60 & 89 & 42 & 7 & 542 \\
\hline
\end{tabular}

casamento fora da microrregião casamento dentro da microrregiáo Fonte: Ciarn. 
De todos os homens e mulheres naturais deste trecho do rio Negro (256 e 223 , respectivamente), $76 \%$ dos homens e $80 \%$ das mulheres continuam residindo nesta mesma microrregião. Esta é uma tendência não constatada nos diferentes trechos de rios das outras sub-regiões; entretanto, é a tendência do centro urbano de Cucuí.

É interessante notar também que dos homens naturais das outras subregiões estudadas, os de Iauaretê estão casados com mulheres de lá mesmo ou do Tiquié/Uaupés; os do Içana e do Tiquié/Uaupés estão casados em sua maioria com mulheres das mesmas regiões; e entre os homens do Negro Acima metade está casada com mulheres de lá, e os outros $50 \%$ com mulheres das outras sub-regiões.

As análises feitas por etnia mostram o que já havia sido relatado pelos diferentes antropólogos especialistas no noroeste amazônico, ou seja, que existe de fato uma permanência da regra da exogamia lingüística para os povos tukano, e da endogamia de povo, para os povos aruak e maku. Pode-se observar ainda que os Tukano têm um maior número de casamentos registrados com os povos tariana, desana e tuyuka e que os Tariana têm um maior número de casamentos com os Tukano e Pira-tapuia. Nota-se ainda que os povos majoritários em suas sub-regiões de origem casam-se com um número maior de etnias diferentes, podendo, assim, estabelecer alianças políticas, econômicas e rituais mais amplas.

Do ponto de vista das trocas por origem geográfica dos cônjuges, confirmase nesta análise que as microrregiões de origem se articulam por intermédio dos casamentos, e nos centros urbanos/missionários não se observou a formação dessas unidades de troca matrimonial. Talvez este fato confirme a hipótese formulada por Goldman (1963) de que o princípio da proximidade geográfica envolve também uma preferência por não casar dentro de sua própria comunidade, sendo imprescindível estabelecer alianças com outras unidades geográficas. Apenas na cidade de São Gabriel pudemos verificar um grande número de casamentos ocorridos neste mesmo centro urbano. É relevante notar que as associações indígenas locais da região, geralmente possuem uma referência geográfica, e não étnica. A maior parte dessas associações representa um trecho de rio, e suas diretorias muitas vezes são compostas por um grupo de irmãos e cunhados.

ANEXO I - Relação de povos e respectivas siglas

Povos de línguas tukano:
AR: Arapaso
BA: Bará
BS: Barasiana
CA: Karapanã 
DE: Desana

JU: Yurutí

KO: Kubeo

MK: Makuna

MI: Mirititapuia

PI: Piratapuia

TA: Tariana ${ }^{13}$

TU: Tukano

TY: Tuyuka

UA: Wanana

Povos de línguas aruak:

BN: Baniwa

BR: Baré

CO: Coripaco

UE: Werekena

Povos de línguas maku:

MA: $\mathrm{Maku}^{14}$

Outros:

d: desconhecida

N: não-índio

\section{Anexo II - Subdivisão dos trechos de rios ou centros missionários das cinco sub-regiões estudadas}

Sub-região de Iauaretê:

- Papuri - margem direita desse rio ou nos igarapés dessa margem;

- Uaupés Acima - margem esquerda do Uaupés acima do povoado de Iauaretê;

- Uaupés - as duas margens desse rio, abaixo do povoado de Iauaretê e até a comunidade de Urubuquara, logo acima da cachoeira de Ipanoré;

- Iauaretê Centro - povoado originado de uma missão salesiana do início do século XX, que hoje em dia conta com 2.800 pessoas. 


\section{Sub-região do Tiquié/Uaupés:}

- Alto Tiquié - desde a fronteira com a Colômbia até as comunidades de São Tomé e Taracuá;

- Baixo Tiquié - desde as comunidades de Cunuri e Tapira Ponta até a foz do Tiquié no Uaupés;

- Uaupés - desde Ipanoré, no médio curso desse rio, logo abaixo da cachoeira do mesmo nome, até a sua foz no rio Negro;

- Taracuá Centro - centro missionário salesiano (como Iauaretê, Assunção do Içana e Pari Cachoeira), formando um povoado em torno de um hospital e uma escola de ensino fundamental;

- Pari Cachoeira Centro - originário também de uma missão salesiana, hoje em dia um povoado que conta com uma escola de ensino fundamental completo; é o segundo maior povoado da região do alto rio Negro, depois de Iauaretê Centro.

\section{Sub-região do Içana:}

- Alto Içana - da fronteira com a Colômbia até Tunuí Cachoeira (inclusive);

- Baixo Içana - de Tunuí Cachoeira (exclusive) até a foz deste rio no Negro, incluindo aí as comunidades do rio Cubate;

- Aiari - afluente do Içana, desde sua foz até as cabeceiras, região próxima do trecho de rio Uaupés Acima, localizado na sub-região de Iauaretê;

- Assunção Centro - centro missionário de tamanho semelhante ao de Taracuá.

\section{Sub-região do Negro Acima:}

- Negro - desde a fronteira com a Colômbia e Venezuela (exclusive o povoado de Cucuí) até antes da comunidade de Bauari;

- Xié - inclui as comunidades das margens desse rio, afluente do Negro;

- Cucuí - centro urbano situado na margem do rio Negro, na fronteira com a Colômbia e Venezuela.

\section{Sub-região do Negro Abaixo:}

- Negro - desde Bauari até a comunidade de Uábada, município vizinho de Santa Isabel;

- São Gabriel da Cachoeira - centro urbano sede do município, onde foram recenseadas as famílias indígenas. 
1 Trata-se do que Ribeiro (1995) chama de "área cultural do rio Negro"; excluiu-se, portanto, os Yanomami. Os povos de língua tukano (todos do grupo tukano oriental) são os seguintes: Barasana, Juruti, Kubeo (Cubeo), Arapaso, Wanana (Uanano), Desana, Karapanã, Piratapuia, Tukano, Mirititapuia, Bara, Carapanã e Tuyuka. Os de língua maku são: Hupdë, Dow e Yuhupdë. Os de língua aruak são: Baniwa, Coripaco, Bare, Werekena e Tariana.

2 Não existe informação, por exemplo, sobre a relação entre irmãos chefes de domicílios numa mesma comunidade, o que seria fundamental para uma análise mais acurada das trocas matrimoniais.

3 Neste trabalho, os termos grupo lingüístico, etnia, povo e tribo são utilizados como sinônimos.

4 Os primos paralelos se distinguem dos primos cruzados por serem filhos de irmãos do mesmo sexo dos seus genitores, isto é, a prima paralela de um homem é a filha da irmã de sua mãe ou do irmão de seu pai.

5 A palavra tukano, guando grafada em itálico, indica todas as etnias falantes de línguas pertencentes ao Tukano Oriental.

6 Entende-se por grupos de fogos a unidade social mínima, geralmente composta por famílias nucleares.

7 A exceção para essa regra é o caso das comunidades maku, como já mencionado.

8 Aqui se faz referência ao mito de origem das diferentes etnias da região, quando a cobra grande, ou anaconda, em cada parada que fazia ao subir ou descer os rios 'paria' o primeiro homem do grupo lingüístico, sua mulher e seu cunhado.

9 Incluem-se aqui os Tariana, uma vez que, apesar de serem falantes de uma língua aruak, estão inseridos há muito tempo no sistema de trocas matrimoniais dos tukano.

10 O Ciarn não pesquisou o sib nem a fratria de cada pessoa, apenas a origem (nascimento) de cada cônjuge e o seu pertencimento a uma determinada etnia.

11 É importante lembrar que o censo foi levado a efeito pela Foirn e suas organizações filiadas em 1992.

12 Neste trabalho é utilizada a idéia de nexo regional formulada por Cabalzar (2000) para explorar o que denominei microrregiões de trocas matrimoniais. Estas microrregiões ou trechos de rios, delimitados para efeito destas análises, são maiores geograficamente do que o conceito de nexo regional e não se interseccionam.

13 Os Tariana falam uma língua aruak; porém, hoje em dia, a maioria fala somente o tukano, convivem e se casam com povos de língua tukano, por isso estão assim classificados.

14 Os Maku foram todos identificados pela família lingüística, pois assim os classificaram os recenseadores na maioria dos casos. 


\section{Referências Bibliográficas}

ADAMS, K. Demographic change and marriage choices in one Carib family. South American Indian Studies, 4:5-10, 1994.

ÅRHEM, K. The Makú, the Makuna and the Guiana System: transformation of social structure in northern Lowland South America. Ethnos, 1-2:5-22, 1989.

BUCHILLET, D. Os índios da região do alto rio Negro. História, etnografia e situação das terras. Laudo elaborado para a demarcação das Terras Indígenas da região, posteriormente revisto para o anticontraditório, 1992. (Mimeo.)

CABAlZAR, A. Organização Social Tuyuka, 1995. Dissertação de Mestrado, São Paulo, Departamento de Antropologia, Programa de Pós-Graduação em Antropologia Social: Universidade de São Paulo.

CABALZAR, A. Descendência e aliança no espaço tuyuka. A noção de nexo regional no noroeste amazônico. Revista de Antropologia, 43:61-88, 2000.

CHERNELA, J. M. Estrutura social no Uaupés. Anuário Antropológico 1981, pp. 59-70, Fortaleza e Rio de Janeiro: Universidade Federal do Ceará e Tempo Brasileiro, 1983.

COIMBRA Jr., C. E. A. et al. The Xavánte in Transition: Health, Ecology and Bioanthropology in Central Brazil. Ann Arbor: University of Michigan Press, 2002.

GOLDMAN, I. The Cubeo Indians of the Northwest Amazon. Urbana: University of Illinois Press, 1963.

HUGH-JONES, C. From the Milk River: Spatial and Temporal Processes in Northwest Amazonia. Cambridge: Cambridge University Press, 1979.

JACKSON, J. Vaupés marriage practices. In: KENSINGER, K. M. (Org.) Marriage Practices in Lowland South America. Urbana: University of Illinois Press, 1984. p.156-179.

LARAIA, R. Arranjos poliândricos na sociedade suruí. Revista do Museu Paulista, XIV:7175, 1963. (Nova Série)

LASMAR, C. De Volta ao Lago do Leite: a experiência da alteridade em São Gabriel da Cachoeira (alto rio Negro), 2002. Tese de Doutorado, Rio de Janeiro: Programa de Pós-Graduação em Antropologia Social, Universidade Federal do Rio de Janeiro.

PAGLiARO, H. A Revolução Demográfica dos Povos Indígenas: a experiência dos Kaiabi do Parque Indígena do Xingu, Mato Grosso (1970-1999), 2002. Tese de Doutorado, São Paulo: Faculdade de Saúde Pública, Universidade de São Paulo.

POZZOBON, J. O mínimo demográfico de um sistema de metades exogâmicas (uma simulação.em computador). Revista Brasileira de Estudos de População, 11:139154, 1994.

RIBEIRO, B. G. Os Índios das Águas Pretas. São Paulo: Companhia das Letras/Edusp, 1995.

SILVERWOOD-COPE, P. L. Os Makú: povo caçador do noroeste amazônico. Brasília: UnB, 1990.

WRIGHT, R. The History and Religion of the Baniwa Peoples of the Upper Rio Negro Valley, 1981. Tese de Doutorado, Ann Arbor: University Microfilms. 